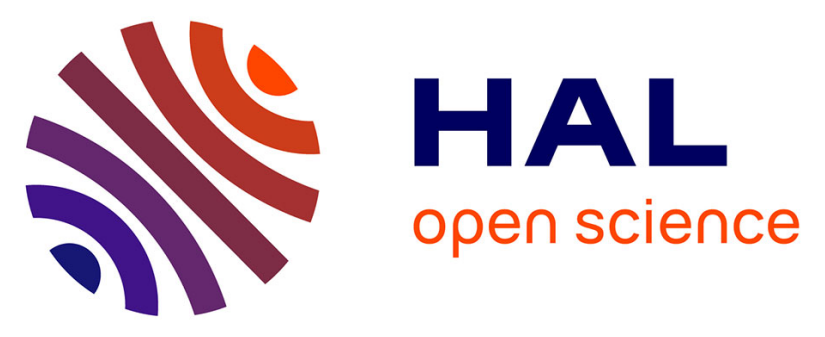

\title{
Thiourea Modified Doxorubicin: A Perspective pH-Sensitive Prodrug
}

\author{
Olga Krasnovskaya, Vladislav Malinnikov, Natalia Dashkova, Vasily \\ Gerasimov, Irina Grishina, Igor Kireev, Svetlana Lavrushkina, Pavel \\ Panchenko, Marina Zakharko, Pavel Ignatov, et al.
}

\section{To cite this version:}

Olga Krasnovskaya, Vladislav Malinnikov, Natalia Dashkova, Vasily Gerasimov, Irina Grishina, et al.. Thiourea Modified Doxorubicin: A Perspective pH-Sensitive Prodrug. Bioconjugate Chemistry, 2019, 30 (3), pp.741-750. 10.1021/acs.bioconjchem.8b00885 . hal-02404558

\section{HAL Id: hal-02404558 \\ https://hal.science/hal-02404558}

Submitted on 30 Dec 2020

HAL is a multi-disciplinary open access archive for the deposit and dissemination of scientific research documents, whether they are published or not. The documents may come from teaching and research institutions in France or abroad, or from public or private research centers.
L'archive ouverte pluridisciplinaire HAL, est destinée au dépôt et à la diffusion de documents scientifiques de niveau recherche, publiés ou non, émanant des établissements d'enseignement et de recherche français ou étrangers, des laboratoires publics ou privés. 


\section{Thiourea Modified Doxorubicin: A Perspective $\mathrm{pH}-$ Sensitive Prodrug}

Olga O. Krasnovskaya, ${ }^{*} \#, \S$ Vladislav M. Malinnikov, ${ }^{\#}$ Natalia S. Dashkova, ${ }^{\#}$ Vasily M. Gerasimov, ${ }^{\perp}$ Irina V. Grishina," Igor I. Kireev, $\|, \bigcirc, \bigcirc$ Svetlana V. Lavrushkina,, Pavel A. Panchenko, ${ }^{\dagger, \perp}$ Marina A. Zakharko, ${ }^{\dagger}$ Pavel A. Ignatov, ${ }^{\perp}$ Olga A. Fedorova, ${ }^{\dagger} \perp$ Gediminas Jonusauskas, Dmitry A. Skvortsov, "Sergey S. Kovalev,", Elena K. Beloglazkina, " Nikolay V. Zyk," and Alexander G. Majouga

\# Department of Chemistry, Lomonosov Moscow State University, Leninskie Gory, 1/3, 119991 Moscow, Russian Federation "Department of Biology, Lomonosov Moscow State University, Leninskie Gory, 1/12, 119234 Moscow, Russian Federation ${ }^{\S}$ Institute of Biochemistry and Genetic Russian Academy of Science (IBG RAS), Ufa Scientific Centre, Oktyabra Prospect 71, 450054 Ufa, Russian Federation

${ }^{\dagger}$ A. N. Nesmeyanov Institute of Organoelement Compounds of Russian Academy of Sciences, Vavilova str. 28, 119991 Moscow, Russian Federation

${ }^{\perp}$ D. Mendeleev University of Chemical Technology of Russia, Miusskaya sqr. 9, 125047 Moscow, Russian Federation

${ }^{\ddagger}$ Laboratoire Ondes et Matière d'Aquitaine (LOMA), UMR CNRS 5798, Bordeaux University, 351 Cours de la Libération, Talence 33405, France

${ }^{\nabla}$ Laboratory of Oncoproteomics, N.N. Blokhin Russian Cancer Research Centre 24, Kashirskoye sh. 115478 Moscow, Russian Federation

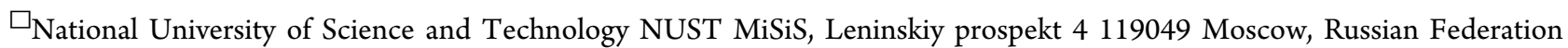

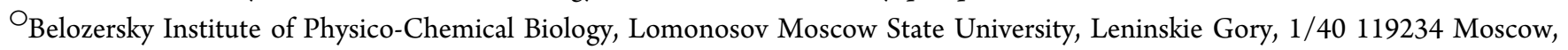
Russian Federation

${ }^{\circ}$ Lab. of Genetic Mechanisms of Development, Kulakov Research Center for Obstetrics, Gynecology and Perinatology, Oparina str., 4117997 Moscow, Russian Federation

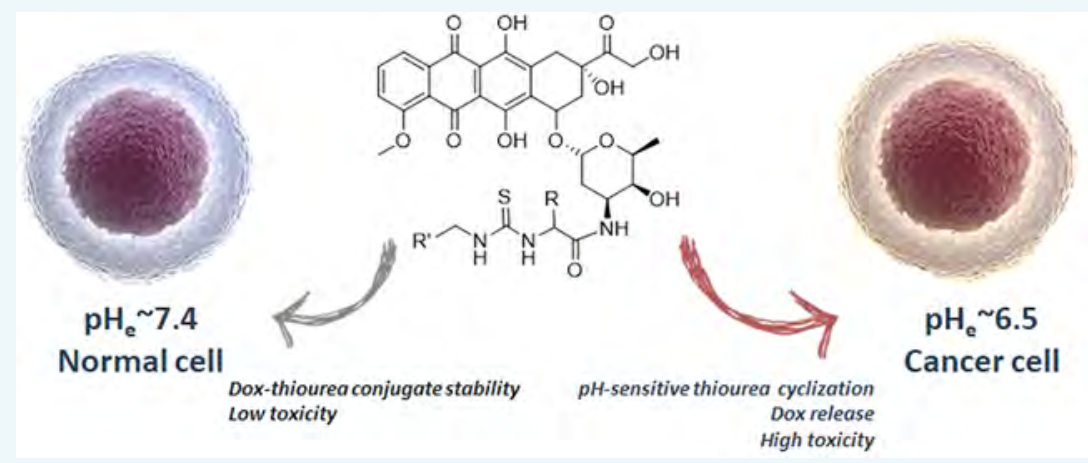

ABSTRACT: A novel approach to the synthesis of $\mathrm{pH}$-sensitive prodrugs has been proposed: thiourea drug modification. Resulting prodrugs can release the cytotoxic agent and the biologically active 2-thiohydantoin in the acidic environment of tumor cells. The concept of acid-catalyzed cyclization of thioureas to 2-thiohydantoins has been proven using a FRET model. Dual prodrugs of model azidothymidine, cytotoxic doxorubicin, and 2-thiohydantoin albutoin were obtained, which release the corresponding drugs in the acidic environment. The resulting doxorubicin prodrug was tested on prostate cancer cells and showed that the thiourea-modified prodrug is less cytotoxic (average IC50 ranging from 0.5584 to $0.9885 \mu \mathrm{M}$ ) than doxorubicin (IC50 ranging from 0.01258 to $0.02559 \mu \mathrm{M}$ ) in neutral $\mathrm{pH} 7.6$ and has similar toxicity (average IC50 ranging from 0.4970 to $0.7994 \mu \mathrm{M}$ ) to doxorubicin (IC50 ranging from 0.2303 to $0.8110 \mu \mathrm{M}$ ) under mildly acidic conditions of cancer cells. Cellular and nuclear accumulation in PC3 tumor cells of Dox prodrug is much higher than accumulation of free doxorubicin.

\section{INTRODUCTION}

Doxorubicin - an antitumor antibiotic - is an effective and commonly used chemotherapeutic agent and is able to embed 
into the double helical structure of cell DNA, inhibiting RNA and DNA synthesis and thereby leading to apoptosis of cancer cells. ${ }^{1}$ Doxorubicin and its modified form doxil are widely used in cancer therapy. ${ }^{2}$ Despite the effectiveness of doxorubicin, there is a high chemotherapeutic failure rate due to its low specificity toward tumor tissues, dose-dependent resistance to therapy, and strong cardiotoxicity. ${ }^{3}$

Development of doxorubicin prodrugs, modified with a target-recognizing fragment, ${ }^{4}$ as well as $\mathrm{pH}$-sensitive prodrugs capable of releasing a cytotoxic agent in weakly acidic tumor tissues, ${ }^{5}$ is a relevant task for medical chemistry.

Acidic extracellular $\mathrm{pH}_{\mathrm{e}}$ is a major feature of tumor tissue; extracellular acidification is considered to occur in the presence of lactic acid, which accumulates due to anaerobic glycolysis in hypoxic cancer cells. ${ }^{6,7}$ Also, the possible reason of acidification is an $\mathrm{CO}_{2}$ accumulation, due to the pentose phosphate pathway, which is highly active within tumor cells, and the following oxidization by the enzyme carbonic anhydrase (CA), which leads to the increase of carbonic acid concentration. ${ }^{8,9}$ Acidic $\mathrm{pH}_{\mathrm{e}}$ not only leads to activation of some lysosomal enzymes but also increases resistance to certain types of chemotherapy, ${ }^{10}$ through the unforeseen metabolism of therapeutic molecules resulting in high outflow of drugs from tumor cells. In particular, acidic $\mathrm{pH}_{\mathrm{e}}$ reduces cytotoxicity of antitumor drugs with weak base $\mathrm{p} K_{\mathrm{a}}$ : doxorubicin, mitoxantrone, and daunorubicin. ${ }^{11}$ In the early stages of breast cancer, the high CAIX enzyme level is a predictive marker of doxorubicin resistance. ${ }^{12}$ Acidic $\mathrm{pH}_{\mathrm{e}}$ also plays a role in the drug resistance of tumor cells due to the increased p-glycoprotein expression, that increases drug efflux. $^{13,14}$

There are several strategies that can be used to develop $\mathrm{pH}$ sensitive prodrugs capable of cytotoxic drug release in the acidic environment of tumor cells, and they are described in many of the newest scientific publications: $\mathrm{pH}$-dependent release of Dox from its micellous conjugate with vitamin $\mathrm{E}$, via $\mathrm{pH}$-sensitive hydrazone bond; ${ }^{15}$ adamantane-modified Dox via $\mathrm{pH}$-sensitive hydrazone linker, capable of releasing free Dox at $\mathrm{pH} 4.5 ;{ }^{16}$ Doxconjugated smart polymeric self-assambled micelles, prepared via an imine linkage, which exhibited the $\mathrm{pH}$-triggered chargeconversion property and accelerated drug release at tumor $\mathrm{pH}^{17}$ polymeric micelles delivery system based on block copolymers of poly(L-lactic acid)- $\beta$-poly(ethylene glycol) $\beta$-poly(L-histidine)-TAT (transactivator of transcription) and poly(Lhistidine)- $\beta$-poly(ethylene glycol). Such micelles have been proven to increase the cytotoxicity of doxorubicin in several multidrug-resistant tumor cell lines through the lifetime increase of the active molecule. ${ }^{18}$ Also, conjugation of docosahexaenoic acid (DHA) to doxorubicin (Dox) with a $\mathrm{pH}$-sensitive hydrazone linker at the 13 position formed a lipophilic prodrug and demonstrated higher anticancer activity in vivo than free doxorubicin; the authors suggested a $\mathrm{pH}$-sensitive Dox release and higher cellular accumulation than free Dox but have not confirmed it experimentally. ${ }^{19}$

We have proposed another approach to the synthesis of $\mathrm{pH}$ sensitive prodrugs, Dox-thiourea drug modification, that would be able to simultaneously release two different therapeutic agents in the acidic $\mathrm{pH}(\mathrm{pH} \geq 6.5 / 7.5) .{ }^{20}$ Thioureas are perspective prodrugs because in the acidic environment of tumor tissues they are cyclized to corresponding thiohydantoins, releasing free doxorubicin. At the same time the resulting thiohydantoin, depending on the structure of the initial thiourea, may have different pharmacological properties. 2-Thiohydantoins exhibit a wide variety of biological properties: antitumor, ${ }^{21}$ antiviral, ${ }^{22}$ anti-inflammatory, ${ }^{23}$ anticonvulsant. ${ }^{24,25}$ One of the most convenient methods of 2 - thiohydantoins synthesis is the acid-catalyzed cyclization of the corresponding thioureas. ${ }^{26}$

In this study, we have chosen thiohydantoin albutoin as a simple structure model drug - an anticonvulsant ${ }^{27,28}$ - that was evaluated by the United States Food and Drug Administration but not approved. ${ }^{29}$ Albutoin, in contrast to the structural similar anticonvulsant diphenylhydantoin, did not not have toxicityinduced side effects. ${ }^{30}$

Doxorubicin is highly hydrophilic and has a short half-life, and its use is associated with severe side effects at high doses. ${ }^{31}$ Doxorubicin implements its cytotoxicity by inhibiting topoisomerase II enzyme. ${ }^{32}$ The amino group in the $3^{\prime}$-position is not essential for topoisomerase II-targeting activities, because it can be replaced by a hydroxyl group without reduction of activity (doxorubicin analog annamycin). However, conjugation of the 3 -amino group through an amide bond reduced the anticancer activity against the leukemia, breast, ovarian, and colon cancer cell lines, suggesting that the presence of a free amino group is required for anticancer activity of doxorubicin. ${ }^{33}$ Thus, we have suggested that the modification of the amino group of doxorubicin with thiourea will reduce the general toxicity of the corresponding prodrug.

To prove the ability of sterically hindered thioureas to cyclize in a weakly acidic medium, we have synthesized a model of $\mathrm{pH}$ sensitive thiourea: a FRET pair based on naphthalenimide and fluorescein. The present paper reports our initial studies on the synthesis of the novel thiourea derivative of doxorubicin - the acid-hydrolyzable twin prodrug by the modification of the N-3' position of Dox through amide bond formation and its anticancer activity. The cytotoxic effects and cellular accumulation of the synthesized compound were evaluated against androgen receptor negative PC3 prostate cancer cell lines.

\section{RESULTS AND DISCUSSION}

The Studies of pH-Sensitive Thioureas-Based Prodrugs Using a FRET-Pair Model. To assess the cyclization of thiourea derivatives in a weakly acidic medium, we have proposed to synthesize a sterically hindered fluorescent derivative of 2-thiohydantoin acid containing the donor naphthalimide and acceptor fluorescein fragments (Scheme 1). In the case of this FRET pair, the Förster resonance energy transfer must be disrupted by acid-catalyzed cyclization, leading to fragmentation of the initial molecule to naphthalenimide and fluorescein components, which will lead to a significant change in the fluorescence spectrum and can be easily monitored by spectral methods (Figure 1).

Thus, the study of FRET-pair fluorescence, where resonant energy transfer is observed, can show whether fluorophores are part of the same molecule or not. In case the acid catalyzed cyclization occurs, the resonance transfer of energy will cease, clearly demonstrating the acid-catalyzed cyclization of thiourea with the release of the amide fragment and the formation of the 2-thiohydantoin.

The spatial structure of the FRET model optimized by molecular mechanics in the gas phase is shown in Figure 2. The calculated distance between the elements of the FRET pair is about $12.8 \AA$, and there is also a significant overlap of the emission spectrum of the donor fragment and the absorption spectrum of acceptor moiety (see section 2.1.2.1), which indicates the possibility of resonant transport in this system. 
Scheme 1. Synthesis of $\mathrm{pH}$-Sensitive Thiourea 10 as a FRETModel Molecule
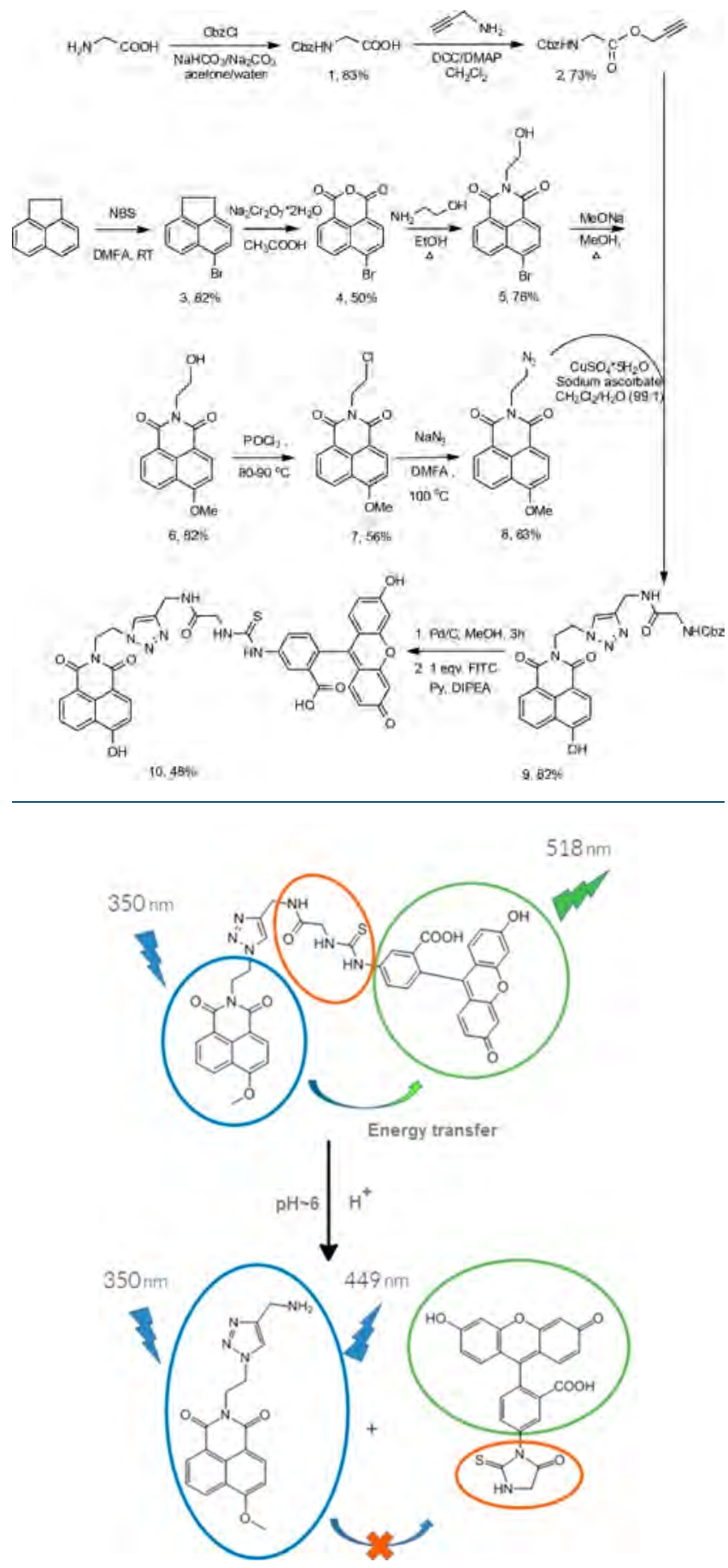

Figure 1. Model $\mathrm{pH}$-sensitive thiourea as a naphthalenimide fluorescein FRET pair.

Synthesis of the $\mathrm{pH}$-Sensitive Thiourea as a FRET-Model Molecule. The synthesis of the FRET pair model (thiourea 10) was carried out according to Scheme 1 .

The FRET pair was synthesized through the ten-stage synthesis, the key stages in which were copper-catalyzed azide-alkyne cycloaddition reaction of propargyl ester $\mathbf{2}$ with azide 8 in mild conditions and the reduction of the resulting triazole 9 with the formation of thiourea 10. Target compounds were isolated by high-performance liquid chromatography.

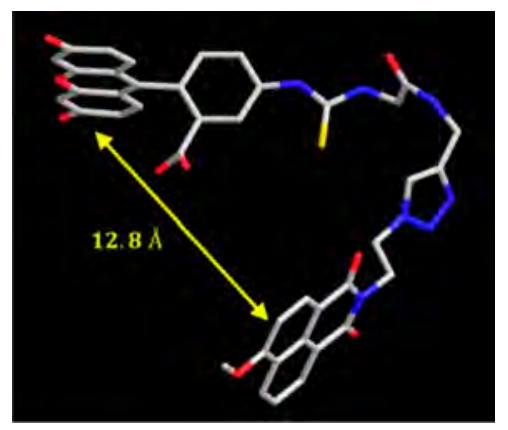

Figure 2. Geometry of a naphthalineimide-fluorescein FRET model optimized by the MM2 method.

The detailed description of the experimental procedures is given in the Supporting Information.

Study of FRET-Model pH-Sensitivity. Theoretical Study of Resonant Energy Transfer in a FRET Model. Effective resonant energy transfer between fluorophores is possible if the distance between them is less than $10 \mathrm{~nm}$, and the emission spectrum of the donor is overlapping with the acceptor absorption spectrum. ${ }^{34}$ The superposition of experimental fluorescence spectra of the donor naphthalimide (NI, compound 6, Scheme 1) and acceptor fluorescein isothiocyanate (FITC) absorption is given in Figure 3.

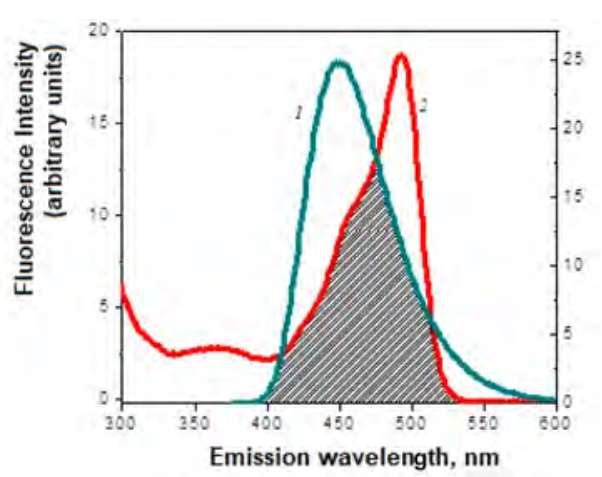

Figure 3. Superposition of the experimentally observed fluorescence spectra of the donor (NI, 1) and acceptor (FITC, 2).

The most important spectral characteristics of fluorophores were determined by the Förster model to calculate the characteristics of resonant transport: the absorption maximum wavelength, the maximum fluorescence wavelength, the extinction coefficient at the absorption maximum, the quantum yield fluorescence, lifetime of the excited state. ${ }^{35}$ The absorption and fluorescence spectra of individual naphthalimide and FITC are shown in Figures S1 and S2 in the Supporting Information. Spectral characteristics of individual chromophores NI (6), FITC, and protonated FITC form in a methanol-water mixture $(\mathrm{v} / \mathrm{v}=1: 1)$ are presented in Table 1.

Results of the calculations based on the experimentally measured spectral characteristics of fluorophores are given in Table 2.

Also, we have studied resonance energy transfer process in the compound 10. Spectrscopic characteristics of $\mathbf{1 0}$ have been analyzed with respect to those of the individual dyes (NI and FITC) as well as with their equimolar mixture. The data obtained indicate the high efficiency of resonant transport in the FRET-pair 10, consistent with the theoretical calculation. For 
Table 1. Spectral Characteristics of Individual Chromophores Ni, FITC, and Protonated FITC Form in a Methanol-Water Mixture (v/v = 1:1)

\begin{tabular}{cccccc} 
Compound & $\lambda_{\max }^{\mathrm{abs}} / \mathrm{HM}$ & $\begin{array}{c}\varepsilon \cdot 10^{-3} / \\
\mathrm{M}^{-1} \cdot \mathrm{cM}^{-1}\end{array}$ & $\begin{array}{c}\lambda_{\max }^{\mathrm{fl}} / \\
\mathrm{HM}\end{array}$ & $\varphi^{\mathrm{fl} *}$ & $\begin{array}{c}\tau_{\mathrm{S}} / \\
\mathrm{HC}\end{array}$ \\
$\begin{array}{c}\text { Naphthalimide NI } \\
\text { (donor) }\end{array}$ & 371 & 8.0 & 449 & 1.0 & 9.0 \\
FITC (acceptor) & 492 & 31.4 & 518 & 0.23 & 3.6 \\
FITC + HCl $\left(10^{-4}\right)$ & $453 ; 480$ & $7.8 ; 7.2$ & 514 & 0.11 & 2.4 \\
\hline
\end{tabular}

experimental details, see the Supporting Information (Figure S3).

Study of Acid-Catalyzed Cyclization of FRET-Model 10 Using Stationary and Time-Resolved Fluorescence Spectroscopy. To investigate the cyclization process of FRET-model 10, a series of solutions at acidic $\mathrm{pH}$ were prepared $\left(5 \times 10^{-6} \mathrm{M}\right.$ of 10) in a water-methanol $(1: 1)$ mixture with $\mathrm{HCl}$ in $0 \mathrm{M}, 1 \times$ $10^{-5} \mathrm{M}$, and $1 \times 10^{-4} \mathrm{M}$ concentrations. The absorption spectra of these mixtures are presented in Figure 4.

The results of stationary fluorescence and fluorescence kinetics analysis are shown in Figure 5 and Figure S4. Fluorescence kinetics (Figure S4) analysis allowed for the calculation of the contribution of an exponent with a characteristic time of $6.0 \mathrm{~ns}$ corresponding to free naphthalimide-which was $52 \%$ (calculated from the known values ${ }^{36}$ of the pre-exponential factors $=619 /(619+561)=0.52)$, i.e. there is an increase in contribution of this component if compared to neutral $\mathrm{pH}$, where it was $37 \%$. In the stationary spectra a significant decrease in the fluorescence intensity of the acceptor $(\lambda=518 \mathrm{~nm})$ and the growth of donor fluorescence intensity $(\lambda$ $=449 \mathrm{~nm}$ ) are also observed, confirming the proposed hypothesis about compound $\mathbf{5}$ decomposition in a weakly acidic medium with the interruption of resonance energy transfer and a change in spectrum of fluorescence.

Thereby, in the studied FRET model of $\mathrm{pH}$-sensitive thiourea an effective resonance energy transfer was observed, but decomposition of thiourea $\mathbf{1 0}$ took place in acidic medium $(\mathrm{pH}=5)$ which was proved by a change in the fluorescence spectrum.

Thus, the hypothesis about the ability of sterically hindered derivatives of 2-thiohydantoin acid to cyclize in a weakly acidic medium was confirmed. Taking this into account it can be assumed the principle possibility of working out of $\mathrm{pH}$-sensitive prodrugs of cytostatic molecules based on the same derivatives, capable of releasing the biologically active substance in the acidic medium of tumor tissue.

pH-Sensitive Thioureas Prodrugs Based on 3'-Amino$3^{\prime}$-deoxythymidine. To develop synthetic approaches to the acid-sensitive thiourea derivatives with sugar moieties we synthesized a model conjugate of the albutoin precursor with 3 '-amino-3'-deoxythymidine.

Synthesis of 3'-Amino-3'-deoxythymidine Analogs of $\mathrm{pH}$ Sensitive Thioureas. After multiple optimizations, we have proposed to introduce the drug fragment at the last stage of the synthesis, through the ester formation of the corresponding

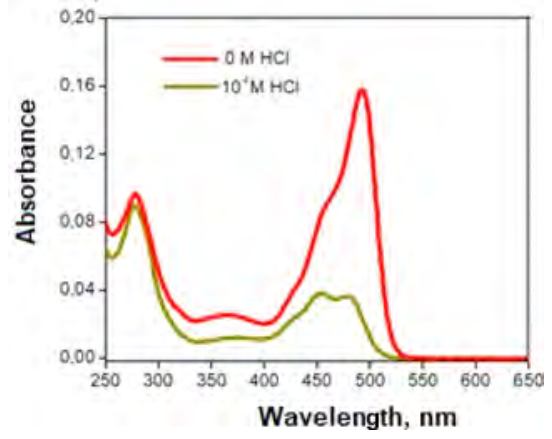

Figure 4. Absorption spectra of the FRET-pair $10\left(5 \times 10^{-6} \mathrm{M}\right)$ in a methanol-water mixture $(\mathrm{v} / \mathrm{v}=1: 1)$ in the presence and absence of hydrochloric acid.

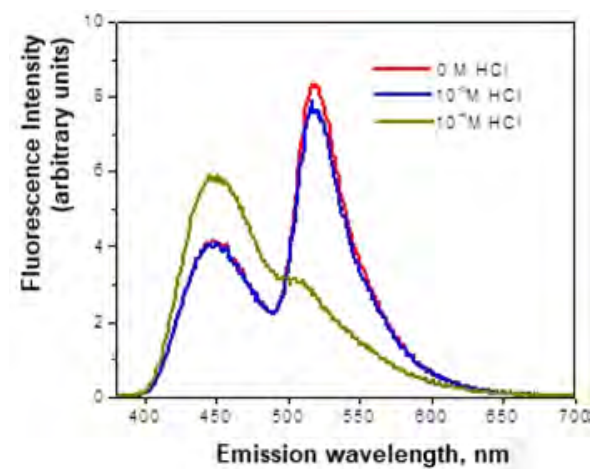

Figure 5. Fluorescence spectra of the FRET-model 10 in a methanolwater mixture $(\mathrm{v} / \mathrm{v}=1: 1)$ in the presence and absence of hydrochloric acid.

thiourea in the reaction with $N$-hydroxysuccinimide as an approach to twin $3^{\prime}$-amino-3'-deoxythymidine-based prodrug (Scheme 2).

Scheme 2. Synthesis of pH-Sensitive 3'-Amino- $3^{\prime}$ deoxythymidine-Albutoin Prodrug 13
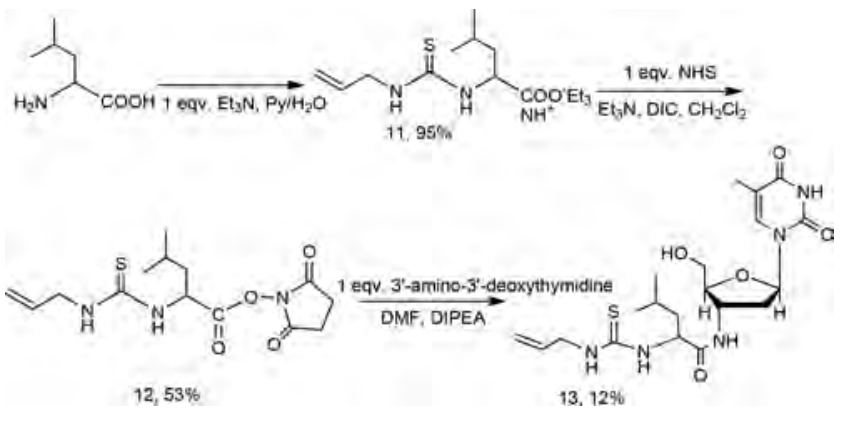

Product 13 was isolated by preparative chromatography on silica gel and characterized by ${ }^{1} \mathrm{H}$ NMR spectroscopy and highresolution mass spectrometry. For a detailed description of the synthesis see the Supporting Information.

Table 2. Theoretical Calculation of the Resonance Energy Transfer Process Characteristics According to the Förster Model in the NI-FIC Compound 10 and in the Protonated Form of NI-FITC

$\begin{array}{lccccc}\text { Compound } & \text { Overlap integral } J(\lambda) \mathrm{L} \cdot \mathrm{nm}^{4} / \mathrm{mol} \cdot \mathrm{cm} & \text { Forster radius } \mathrm{R} 0 / \AA & r / \AA & k_{\text {FRET }} / \mathrm{c}^{-1} & \Phi_{\text {FRET }(\text { FRET efficiency) }} \\ \text { FRET model } & 4.35 \times 10^{14} & 44.7 & 12.8 & 2.0 \times 10^{11} \\ \text { FRET model }+\mathrm{H}^{+} & 2.08 \times 10^{14} & 39.5 & 0.9994 & 12.8 & 9.6 \times 10^{10}\end{array}$


Evaluation of $\mathrm{pH}$-Sensitivity of Twin 3'-Amino-3'-deoxythymidine-Based Prodrug 13 by LC-MS. The thiourea-based prodrugs should release a biologically active substance and thiohydantoine in a weakly acidic medium. The model drug release from the conjugate of $3^{\prime}$-amino- $3^{\prime}$-deoxythymidine with albutoin precursor 13 was studied in vitro under physiological conditions at different $\mathrm{pH}$ 's.

Compound 13 was dissolved in formate buffer solutions with a $\mathrm{pH}$ of $5.5 ; 6.5 ; 7.4$. The resulting mixtures were incubated at 37 ${ }^{\circ} \mathrm{C}$ for $24 \mathrm{~h}$. Samples for analysis were taken at different time intervals, 0, 20, 40, 60, 90, 120, 240, 480, $1440 \mathrm{~min}$, and analyzed by the LC-MS method. Relative rates of hydrolysis of the compound 13 over a 48 -h period were calculated using the percent of prodrug 13 hydrolysis in acidic conditions; the relative rate of free aminothymidine accumulation was also measured. The conjugate $\mathbf{1 3}$ flow rate is shown in Figure 6, and

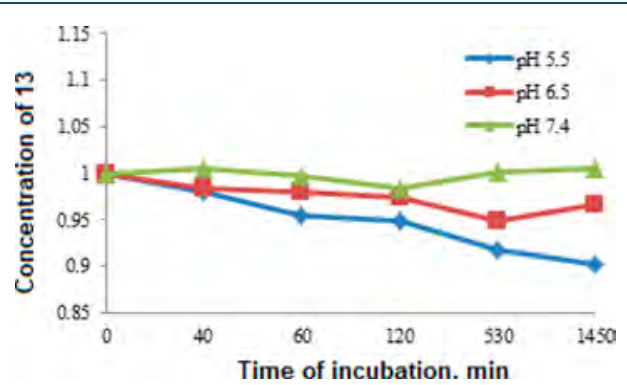

Figure 6. Dependence of prodrug 13 concentration from the time of incubation in medium with different $\mathrm{pH}$ 's.

the accumulation rate of the cyclization product $3^{\prime}$-amino- $3^{\prime}$ deoxythymidine is shown in Figure 7 . We have suggested the following scheme for the release of 3 '-amino-3'-deoxythymidine and albutoin, which proceeds in a slightly acidic solution $\mathrm{pH} \sim$ 6.5 (Scheme 3).

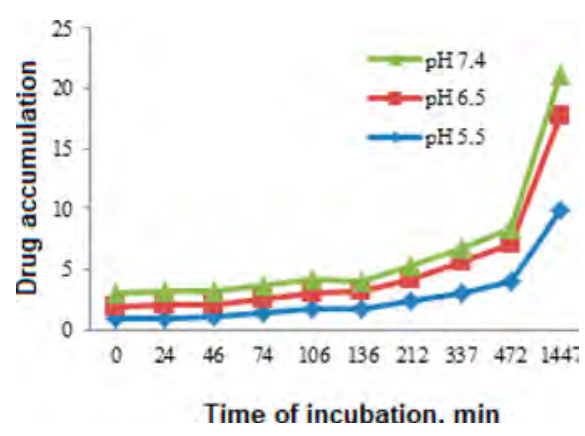

Figure 7. Dependence of $3^{\prime}$-amino- $3^{\prime}$-deoxythymidine concentration from the time of incubation in medium with different $\mathrm{pH}$ 's.

Scheme 3. Proposed Way of Acid-Catalyzed Decomposition of the Model Conjugate 13 in a Weakly Acidic Medium

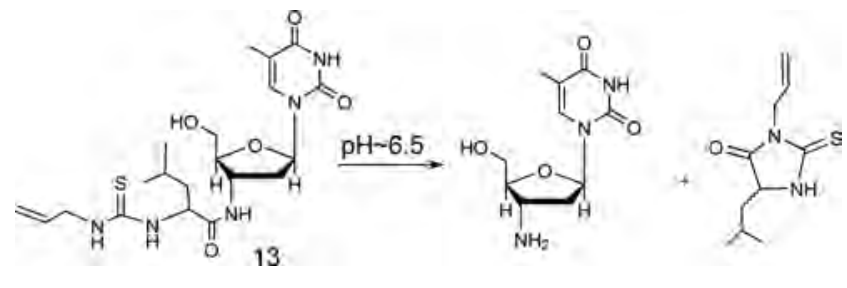

We also have determined the kinetic parameters of this process. The reaction order for both the product and the reagent is zero. The ratio of the rate constants of the process at $\mathrm{pH} 7.4$ (k1), pH $6.5(\mathrm{k} 2)$, and $\mathrm{pH} 5.5(\mathrm{k} 3)$ was $\mathrm{k} 1: \mathrm{k} 2: \mathrm{k} 3=1: 6.6: 8.5$. This data indicates the almost 10 -fold increase in the rate of aminothymidine release at $\mathrm{pH}=5.5$ compared to neutral medium ( $\mathrm{pH}=7.4)$.

It should be noted that during the LC-MS analysis of compound 13 the signal of albutoin $(m / z=211.0911)$ was observed in all cases, which confirms that the cyclization reaction proceeds according with Scheme 3.

Thus, the resulting conjugate $\mathbf{1 3}$ is capable of releasing the starting drug and albutoin in a weakly acidic medium, but practically it does not disintegrate under neutral conditions. This suggests that such compounds in in vivo models would be selectively released in tumors $(\mathrm{pH} \sim 6.5),{ }^{37}$ while in healthy tissues release of the drug should not occur.

Based on our result, we conclude that the cyclization of thioureas prodrug can occur under conditions corresponding to the tumor tissue. The next step is the synthesis of the anticancer drug (doxorubicin)-based thioureas.

pH-Sensitive Thiourea Prodrug Based on Doxorubicin. We have proposed a synthesis of twin doxorubicin-albutoin prodrug that can possess both antitumor and anticonvulsant properties. It was suggested that the introduction of an albutoin precursor fragment would reduce the toxicity in the neutral $\mathrm{pH}$ due to a significant change in the structure of the initial cytotoxic agent, but such a molecule will be able to release the initial drug in a weakly acidic $\mathrm{pH}$ of the tumor tissue medium, and also, higher lipophilicity of the thiourea-doxorubicin prodrug should improve cell penetration compared to unmodified doxorubicin, thereby lowering the effective drug dose reducing toxicity.

Synthesis of Doxorubicin Derivative of $\mathrm{pH}$-Sensitive Thiourea. To obtain a twin doxorubicin-based prodrug 14 we have used a previously described three-step approach with intermediate preparation of the $\mathrm{N}$-hydroxysuccinimide ester $\mathbf{1 2}$. The synthesis was carried out according to Scheme 4.

Scheme 4. Synthesis of $\mathrm{pH}-$ Sensitive Doxorubicin-Albutoin Prodrug 14

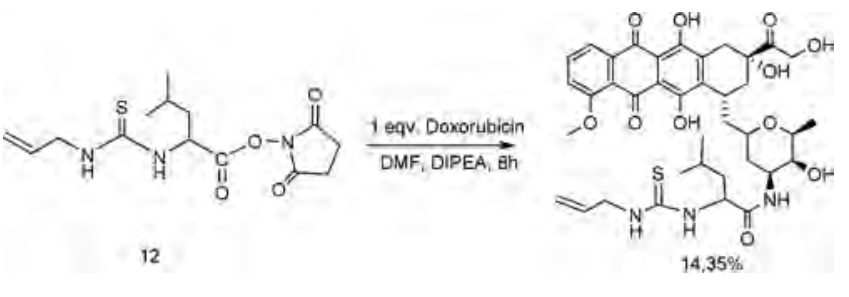

The product 14 was isolated by preparative chromatography on silica gel and characterized by ${ }^{1} \mathrm{H}$ NMR spectroscopy and high-resolution mass spectrometry. For a detailed description see the Supporting Information.

Evaluation of pH-Sensitivity of Twin Doxorubicin-Albutoin Prodrug 14 by LC-MS. Relative rates of compound 14 hydrolysis over a 48 -h period were evaluated using the experimentally determined percentage of the initial doxorubicin-albutoin prodrug 14 under hydrolysis in acidic conditions at different $\mathrm{pH}$ 's.

Prodrug $\mathbf{1 4}$ was incubated in aqueous formate buffer at $\mathrm{pH}$ $5.5,6.5$, and 7.4 at $37{ }^{\circ} \mathrm{C}$ over a 20 -h period. The LC-MS technique was employed to analyze how much of compound 14 was hydrolyzed. We have demonstrated the ability of the derivative 14 to enter the acid-catalyzed cyclization reaction with the formation of albutoin and doxorubicin in a weakly acid 
solution. Sampling for LC-MS analysis was carried out at 0, 70, and $1210 \mathrm{~min}$. The content of the initial conjugate was evaluated; the resulting concentration/time dependence in semilogarithmic coordinates is shown in Figure 8.

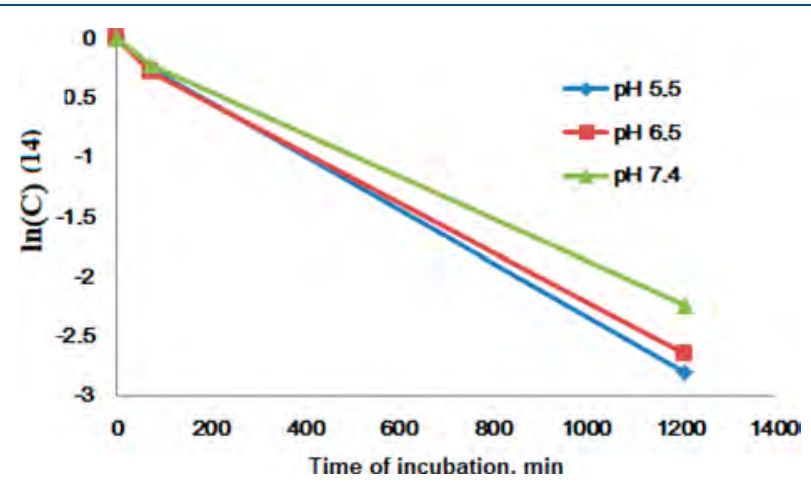

Figure 8. Semilogarithmic dependence concentration of compound 14 on time incubation at various $\mathrm{pH}$ conditions.

We have suggested the following scheme for the release of doxorubicin and albutoin, which proceeds in a slightly acidic solution $\mathrm{pH} \sim 6.5$ (Scheme 5$)$.

Scheme 5. Proposed Way of Acid-Catalyzed Decomposition of the Twin Doxorubicin-Albutoin Prodrug 14 in a Weakly Acidic Medium

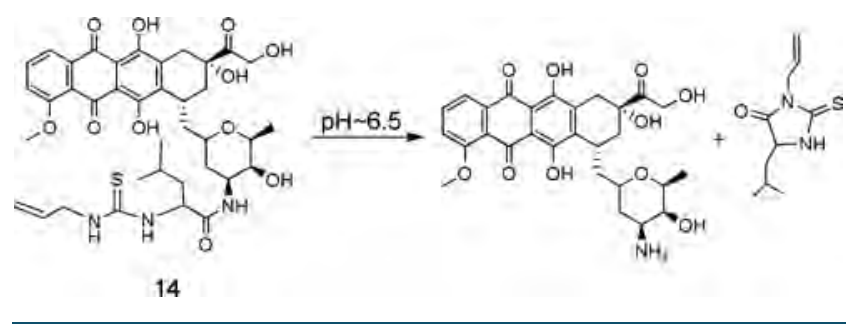

The release of free doxorubicin reaches a value of $94 \%$ at $\mathrm{pH}=$ $5.5 ; 93 \%$ at $\mathrm{pH}=6.5$; and $89 \%$ at $\mathrm{pH}=7.4$. Analysis of the data in semilogarithmic coordinates allows for assumption of the first order of the reaction for the conjugate 14. On this base, the halftransformation times at different $\mathrm{pH}$ values were calculated, which are $300 \mathrm{~min}$ at $\mathrm{pH}=5.5 ; 320 \mathrm{~min}$ at $\mathrm{pH}=6.5$; and 380 $\min$ at $\mathrm{pH}=7.4$.

Thus, the hypothesis of faster release of conjugate $\mathbf{1 4}$ in an acid medium was confirmed.

Previously, the fatty acid derivatives of doxorubicin have been synthesized. ${ }^{38}$ These prodrugs are amides, and they possess generally lower toxicity compared to doxorubicin, which was explained by the high stability of amides to nonenzymatic hydrolysis under physiological conditions. Also, recently, adamantane-modified doxorubicin via amide and ester linkers was developed, and, also, these conjugates were found to be nontoxic and did not show the ability to release free Dox in weakly acidic medium. ${ }^{16}$

Thereby, previous attempts to obtain $\mathrm{pH}$-sensitive prodrugs of doxorubicin, by modifying the $3^{\prime}-\mathrm{NH}_{2}$ position with an amide bond, did not give satisfactory results on drug release and toxicity. The proposed concept of thiourea modification shows a proton-sensitive release even at $\mathrm{pH}$ 6.5. Due to the special structure of the introduced thiourea fragment, the resulting prodrug does not undergo hydrolysis according to the classical mechanism of amide hydrolysis, instead initiating the formation of a 2-thiohydantoin derivative with the release of the amide fragment. This reaction, unlike the hydrolysis of amides, easily occurs in weakly acidic media. The next step was to study the effect of thiourea modification on cytotoxicity.

In Vitro Studies of Compound 14 Cytotoxicity against PC3 Cell Line under Pre-Established Acidic Cancer Cell Culture Medium $(\mathrm{pH}<7.0)$. After the studying the $\mathrm{pH}$-sensitive dual prodrug 14 ability to release doxorubicin and albutoin in an acidic environment, we studied the effect of compound 14 on tumor cells of prostate cancer PC3. The cells treated with the same concentration of free doxorubicin were used as negative controls.

We have prepared two different cell cultures for comparison: one was incubated in standard nutrient medium with $\mathrm{pH}=7.6$, and the other one was adapted to conditions of tumor tissue with $\mathrm{pH}=6.6$. Previously it has been shown that a $\mathrm{pH}$ decrease of the nutrient medium from 7.4 to 6.7 does not affect the growth rate and the population of cells. ${ }^{39}$ This means that the cytotoxicity can be attributed exclusively to the effect of the test drug but not to the change in external conditions.

Doxorubicin prodrug 14 and free doxorubicin were added to the aforementioned cultures. The MTT method ${ }^{40}$ was used to study cell survival after incubation for $48 \mathrm{~h}$.

We have detected a decrease in the toxicity of the conjugate 14 under study in a weakly alkaline medium corresponding to healthy tissues, compared with its toxicity in more acidic medium. IC50 values for doxorubicin prodrug 14 and doxorubicin in various media also were calculated and were found to be dramatically different (Table 3 ). The cytotoxicity curves of 14 and Dox at different concentrations are given in the Supporting Information (Figure S5).

Table 3. IC50 Values of Doxorubicin Prodrug 14 and Free Doxorubicin against PC3 Cells

\begin{tabular}{ccccc}
$\begin{array}{c}\text { IC50, } \\
\mu \mathrm{M}\end{array}$ & $\mathrm{pH}=6.6$ & & $\mathrm{pH}=7.6$ & \\
average & Doxorubicin & $\mathbf{1 4}$ & $\begin{array}{l}\text { Doxorubicin } \\
\text { (4) }\end{array}$ & $\mathbf{1 4}$ \\
& 0.4322 & 0.6303 & 0.01794 & 0.7430 \\
95\% confidence intervals & & & \\
0.2303 to & 0.4970 to & 0.01258 to & 0.5584 to \\
0.8110 & 0.7994 & 0.02559 & 0.9885 \\
\hline
\end{tabular}

Such different IC50 values for doxorubucin in different $\mathrm{pH}$ 's can be explained by low cellular penetration, which occurs due to protonation. In addition to lipophilicity, the degree of molecular ionization, which is dependent on $\mathrm{pH}$ and $\mathrm{p} K_{\mathrm{a}}$ determines the transport action. Doxorubicin acts as a weak base $\left(\mathrm{p} K_{\mathrm{a}} 8.34\right){ }^{41}$ Therefore, a decreasing extracellular $\mathrm{pH}$ leads to an increasing ionization of drug molecules, and, hence, drug transport into cells is rendered more difficult. ${ }^{42}$

Thus, due to $\mathrm{p} K_{\mathrm{a}}$ value, doxorubicin shows increased toxicity to $\mathrm{pH}$-neutral healthy tissues compared with $\mathrm{pH}$-acidic tumor tissues; therefore, more hypophilic and penetrating prodrugs are promising analogues. Comparison of the cellular penetration of prodrug 14 with free doxorubicin is given in 2.3.4.

At $\mathrm{pH}=7.6$ high-lipophilic conjugate 14 penetrates into the cells, but Dox release does not take place sufficiently. However, a rather high toxicity even in a neutral medium compared to the low toxicity of prodrugs incapable of release ${ }^{16}$ suggests Dox releasing inside the cell in a weakly acidic environment of the endosomes $(\mathrm{pH} \sim 6.0)$. This explains the similarity of the cytotoxicity values of $\mathbf{1 4}$ at different acidities of the medium - in 
both experiments, one substance acts by one mechanism - most likely, topoisomerase II inhibition.

Thus, the resulting conjugate $\mathbf{1 4}$ has toxicity similar to doxorubicin in a tumor tissue environment and is 30 times less toxic in a healthy tissue environment.

Cellular Accumulation Studies of Compound 14 in the PC3 Cell Line. To study the cell penetration ability of 14 and comparison of penetration with doxorubicin, we have investigated intracellular accumulation in PC3 cells after $2 \mathrm{~h}$ of incubation with 14 and Dox. The results are shown in Figures 9 (PC3 cells) and 10 (PC3 cells labeled with DAPI).

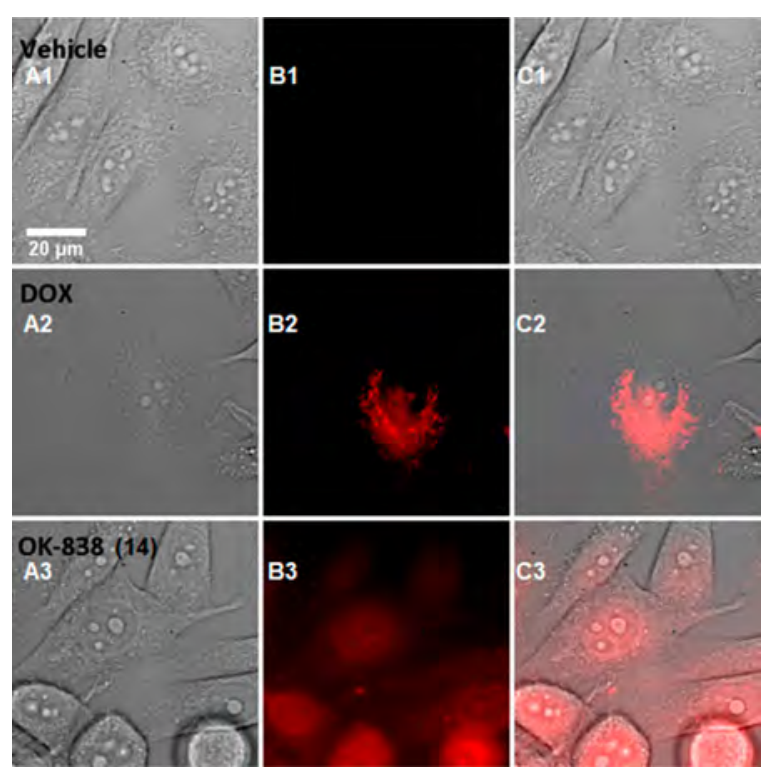

Figure 9. Cellular accumulation of 14 in PC3 cells: (A) PC3 cells treated with water (A1), doxorubicin (A2), and 14 (A3); (B) visualization of drugs in the red fluorescent channel $(561 \mathrm{~nm})$; and (C) merge of $A$ and $B$.
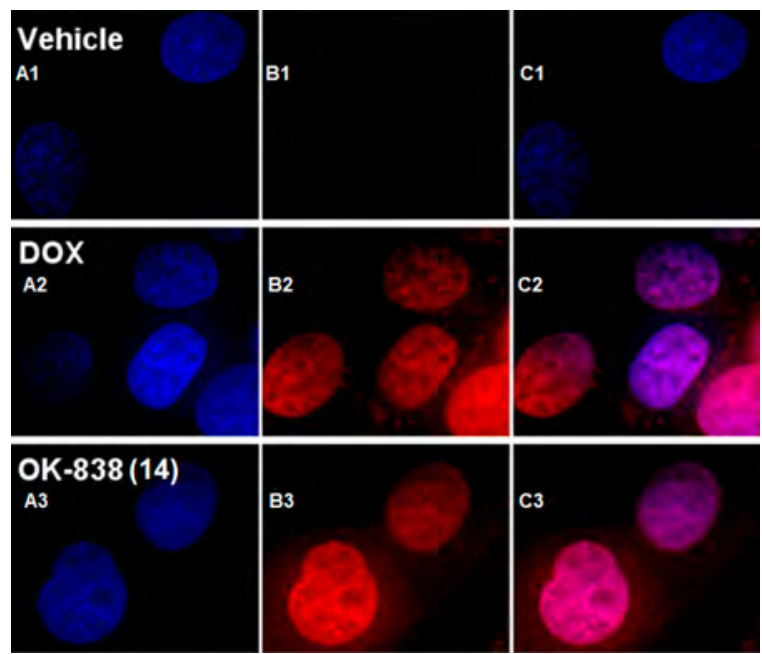

Figure 10. Cell nucleus accumulation of 14 in DAPI-labeled PC 3 cells: (A) DAPI-labeled PC3 cells treated with water (A1), doxorubicin (A2), and 14 (A3), vizualization of DAPI in blue fluorescent channel (450 $\mathrm{nm}) ;(\mathrm{B})$ visualization of drugs in the red fluorescent channel (561 $\mathrm{nm})$; and (C) merge of $\mathrm{A}$ and $\mathrm{B}$.

Transport of anthracyclines is essentially influenced by the parameters $\mathrm{p} K_{\mathrm{a}}$ and polarity of the molecule. The intracellular drug concentration at steady state increases with increasing lipophilicity in the order doxorubicin, epirubicin, and aclacinomycin. ${ }^{42}$ As we expected, 14 penetrates the cell much better than doxorubicin due to increased lipophilicity.

After penetrating the cell membrane and releasing from the endosome, most likely we observe a mixed signal of Dox, which has released from 14, and the conjugate 14 (Figure 9, C3).

Also, high nucleous accumulation was observed (Figure 10, C3). It is well-known, that Dox is capable of nuclear accumulation, resulting in topoisomerase II inhibition. ${ }^{43}$ Prodrug 14, as well as higher cellular penetration, shows higher nuclear penetration in comparison with free doxorubicin (Figure $10, \mathrm{C} 3$ ), which indicates that the prodrug 14, which did not undergo hydrolysis in the proteasome, penetrates into the cell nucleus as easily as into the cell, due to its lipophilicity. Also, cell nuclei accumulation was quantified, and average fluorescence signals for prodrug $\mathbf{1 4}$ and doxorubicin are presented in the Supporting Information (Figure S6, Table S1).

It should be noted that doxorubicin is not protonated in neutral $\mathrm{pH} 7.4$ and possesses a strong cytotoxic effect (Table 3), but its penetration into the cell and nuclei is still extremely low (Figures 9, 10, C2).

In the acidic $\mathrm{pH}$ of the tumor cells in vivo, doxorubicin will be protonated and shows even lower cellular accumulation. This would lead to a low effective dose of the drug and high toxicity.

Bioconjugation, an attachment of a bioactive molecule to another molecule via a covalent bond, leads to the formation of a novel chemical structure with may have enhanced properties compared to those of the original molecule. At the same time, as can be seen from the literature data, the bioconjugation of various molecules to doxorubicin often leads to a rapid decline in cytotoxic activity and biodistribution failure. Conjugating the dexamethasone molecule to Dox results in a more lipophilic conjugate, which also, like prodrug 14 , more easily penetrates into the cell compared to the original doxorubicin. However, the conjugate with dexomethasone showed no ability to accumulate in the cell nuclei and also, as in the examples described above, shows toxicity to MCF-7 cells more than 20 times less compared to Dox. ${ }^{44}$ Prodrug 14, due to the $\mathrm{pH}$-sensitive thiourea fragment, which increases the lipophilicity of the molecule, distribution rate, but which at the same time can be easily removed by cyclization, easily penetrates both into the cell and into cell nuclei.

Conjugate $\mathbf{1 4}$ is less toxic than doxorubicin in neutral $\mathrm{pH}$ (Table 3); however, it exhibits better cellular accumulation even at this $\mathrm{pH}$ value; at $\mathrm{pH} 6.5,14$ shows toxicity similar to doxorubicin (Table 3), due to a combination of high cellular penetration and $\mathrm{pH}$-sensitive release doxorubicin and albutoin.

\section{CONCLUSION}

Summarizing the results, we have developed a methodology for the preparation of a naphthalimide-fluorescein FRET pair, which contains in the structure the fragment of thiohydantoin acid and is capable of an acid-catalyzed cyclization. The presence of resonant energy transfer in this system was predicted theoretically and confirmed experimentally, and the hypothesis about the FRET-pair cyclization in a weakly acidic medium was proved.

The method for the synthesis of a new $\mathrm{pH}$-sensitive twin doxorubicin-thiourea prodrug was proposed. The ability of the resulting prodrug 14 to release cytotoxic and thiohydantoin components in a weakly acidic medium was confirmed. Using in vitro cytotoxicity studies, the selectivity of the $\mathrm{pH}$-sensitive twin 
doxorubicin-albutoin prodrug toward PC3 prostate cancer cell line was compared to free doxorubicin. It was shown that the obtaining $\mathrm{pH}$-sensitive twin doxorubicin-albutoin prodrug has more than a 30 -fold selectivity increase toward healthy tissues compared to the free doxorubicin. Despite the fact that in neutral $\mathrm{pH}$ the toxicity of Dox and prodrug 14 is dramatically different, in acidic $\mathrm{pH}$ it is almost equal. Thiourea-modified doxorubicin 14 has shown better cellular and nuclei penetration in comparison with free Dox. Thus, the proposed approach to the modification of doxorubicin with $\mathrm{pH}$-sensitive thioureas opens up possibilities for obtaining drugs of the same pharmacological efficacy on tumor tissues having a lower effective dose due to higher cellular penetration and the possibility of adding a second pharmacological action depending on the structure of the released thiohydantoin.

\section{MATERIALS AND METHODS}

Chemicals. Unless otherwise noted, all preparations were carried out in reagent grade solvents. All chemicals used in the synthesis were obtained from Acros or Sigma-Aldrich and were used without further purification. Solvents were deoxygenated/ distilled/purified by bubbling through a stream of argon or by conventional methods and dried over molecular sieves. Column chromatography was performed using silica gel 60-120 mesh, 100-200 mesh.

${ }^{1}$ H NMR spectra were recorded on a Bruker-Avance instrument (operating at $400 \mathrm{MHz}$ for $1 \mathrm{H}$ ). As the solvent, deuterochloroform $\left(\mathrm{CDCl}_{3}\right)$ and dimethyl sulfoxide-d6 (DMSO- $\left.d_{6}\right)$ were used. Chemical shifts are given in parts per million on a scale $\delta$ with respect to hexamethyldisiloxane as an internal standard.

High Resolution Mass Spectra (HRMS) were recorded on an Orbitrap Elite (Thermo Scientific) mass spectrometer with an IRET. To inject solutions with a concentration of 0.1 to $9 \mu \mathrm{g} /$ $\mathrm{mL}$ (in $1 \%$ formic acid in acetonitrile), direct injection into the ion source using a syringe pump $(5 \mu \mathrm{L} / \mathrm{min})$ was used. The spray voltage is $\pm 3.5 \mathrm{kV}$, and the temperature of the capillary is $275^{\circ} \mathrm{C}$. Mass spectra were recorded using an Orbitrap analyzer with a resolution of 480,000 ( 1 microscan). The maximum input time is $900 \mathrm{~ms}$, averaging over 9 spectra; the mass range is $90-$ $2000 \mathrm{Da}$, and in some cases it is $200-4000 \mathrm{Da}$. For internal calibration, DMSO and diisooctyl phthalate signals $(\mathrm{m} / \mathrm{z}$ 157.03515 and 413.26623$)$ were used in the positive mode, and the dodecyl sulfate signal $(\mathrm{m} / z 265.14790)$ was used in the negative mode.

LCMS. For purification and analysis of samples we used the Shimadzu Prominence LC-20 system with a column oven and fraction collector coupled to a single quadrupole massspectrometer Shimadzu LCMS-2020 with a dual DUIS-ESIAPCI ionization source. The analytical and preparative column was Phenomenex Luna $3 \mathrm{u} \mathrm{C18} \mathrm{100A} \mathrm{(150 \times 4.6} \mathrm{mm).} \mathrm{The}$ mobile phases were as follows: A - $0.1 \%$ formic acid in water, B $10 \mathrm{mM}$ ammonium formate in water, D - acetonitrile.

LCMS parameters for analyses were as follows: gradient flow of $1 \mathrm{~mL} / \mathrm{min}(0-0.5 \mathrm{~min}-5 \% \mathrm{D}, 0.5-10.5 \mathrm{~min}-5 \%$ to $100 \% \mathrm{D}$, $10.5-12 \mathrm{~min}-100 \% \mathrm{D}, 12-14.5 \mathrm{~min}-100 \%$ to $5 \% \mathrm{D}$ ), column oven temperature $40{ }^{\circ} \mathrm{C}$, optional UV detection of some compounds.

MS parameters were as follows: drying gas $15.0 \mathrm{~L} / \mathrm{min}$, nebulizing gas $1.5 \mathrm{~L} / \mathrm{min}$, DL temperature $250{ }^{\circ} \mathrm{C}$, heat block temperature $400{ }^{\circ} \mathrm{C}$, interface voltage $-3.5 \mathrm{kV}$, corona needle voltage $-3.5 \mathrm{kV}$. Positive (mass range $250-2000 \mathrm{Da}$, in some cases $155-2000 \mathrm{Da}$ ) and negative ions (mass range 215-2000 $\mathrm{Da})$ were registered. For hydrolysis kinetics study the SIM mode was used with registration of the molecular ions and adducts $[\mathrm{M}$ $+\mathrm{H}]^{+},[\mathrm{M}+\mathrm{Na}]^{+},[\mathrm{M}+\mathrm{K}]^{+},[\mathrm{M}-\mathrm{H}]^{-},[\mathrm{M}+\mathrm{HCOO}]^{-}$.

HPLC. For purification of Fret-pair 10 we used identical LC parameters except gradient which was tailored for this compound (0-0.5 $\mathrm{min}-35 \% \mathrm{D}, 0.5-5.5 \mathrm{~min}-35 \%$ to $55 \%$ D, $5.5-9.5 \mathrm{~min}-55 \%$ to $100 \% \mathrm{D}, 9.5-10.5 \mathrm{~min}-100 \% \mathrm{D}, 10.5-$ $14 \mathrm{~min}-100 \%$ to $35 \% \mathrm{D})$. Fractionation was based on UV detection only (absorbance on $485 \mathrm{~nm}$ ); fractions were collected based on UV signal level and slope.

Analytical Thin-Layer Chromatography. TLC was performed on Merck silica gel aluminum plates with F-254 indicator. Compounds were visualized by irradiation with UV light or iodine staining.

Geometry Estimation of Naphthalineimide-Fluorescein FRET-Model 10 Optimized by the PM6 Semiempirical Method. The three-dimensional structure of $\mathbf{1 0}$ was built with the MOPAC 2016 program package using the PM6 semiempirical method. ${ }^{45}$ The calculations were performed at optimized geometries, which reached gradient variations of less than $0.01 \mathrm{kcal} / \mathrm{mol}$. The solvent effect was included in geometry optimizations following the Conductorlike Screening Model (COSMO) implemented in MOPAC. A dielectric constant of $\varepsilon=60$ and a refraction index of solvent $(n)$ such that $n 2=2$ were used

Experimental Study of Resonant Energy Transfer in the FRET Model. To confirm the presence of resonant energy transfer in the FRET model, the absorption and fluorescence spectra of the equimolar mixture naphthalimide + fluorescein isothiocyanate $\left(\mathrm{NI} 5 \times 10^{-6} \mathrm{M}+\right.$ FITC $\left.5 \times 10^{-6} \mathrm{M}\right)$ and the solution of FRET-model $5 * 10^{-6} \mathrm{M}$ were compared (excitation wavelength $370 \mathrm{~nm}$ ) (Figure S3). Due to the instability of the FRET model, there was a partial decay during transportation to the place of investigation according to Figure S3. This resulted in the destruction of the FRET pair with the release of the compound containing the naphthalimide moiety. This process causes the appearance of an additional peak of fluorescence at $\lambda$ $=449 \mathrm{~nm}$. The time-resolved fluorescence spectra of the FRET model and naphthalimide were also recorded. The results are presented in the form of spectral-temporal maps and a plot of fluorescence intensity at different wavelengths versus time (Figure S3). It was found that the lifetime of the excited impurity state is $5.6 \mathrm{~ns}$, and that of the test compound is $3.0 \mathrm{~ns}$. The contribution of the exponential with the characteristic time 5.6 ns corresponding to the naphthalimide-containing impurity is $37 \%$ (calculated from the known values of the pre-exponential factors as $976 /(976+1612)=0.37)$. Taking into account the difference between the quantum yields of the fluorescence FRET model and naphthalimide, it was found that the impurity content is approximately $15 \%$. Fluorescence of the acceptorfluorescein appears almost immediately after photoexcitation; fast relaxation of naphthalimide with a simultaneous rapid increase in the fluorescence intensity of the acceptor is not observed. The obtained data indicate the high efficiency of resonant transport in the system under investigation, consistent with the theoretical calculation. Spectral-temporal maps of the fluorescence FRET model and naphthalimide, fluorescence kinetics of the FRET model are shown in the Supporting Information (Figure S3).

Adaptation of PC3 Culture Cells to $\mathrm{pH}=6.6$. The PC3 line cells were incubated in the medium at $t=37{ }^{\circ} \mathrm{C}$ until spontaneous $\mathrm{pH}=6.7$. The cells were then transferred twice to RPMI-1640 medium with $\mathrm{pH}=6.7$ to adapt to a weakly acidic medium. After adaptation for $24 \mathrm{~h}$, the $\mathrm{pH}$ of the medium was 
adjusted to 6.6 using $\mathrm{KH}_{2} \mathrm{PO}_{4}$. Cells were incubated in acidic medium for $48 \mathrm{~h}$.

Cytotoxicity Study of 14. PC3 line cells incubated at $\mathrm{pH}$ 6.6 were suspended and transferred to 2 plates per 96 wells. Similarly, the culture of PC3 cells incubated at $\mathrm{pH}=7.6$ was reported. Subsequently, solutions of 14 and Doxorubicin in concentrations of $1 \times 10^{-4} \mathrm{~g} / \mathrm{L}, 1 \times 10^{-3} \mathrm{~g} / \mathrm{L}, 1 \times 10^{-2} \mathrm{~g} / \mathrm{L}, 1 \times$ $10^{-1} \mathrm{~g} / \mathrm{L}$, and $1 \mathrm{~g} / \mathrm{L}$ was added to both cell cultures. Cells were incubated for $48 \mathrm{~h}$. Then, using the MTT method (using 3-(4,5dimethylthiazol-2-yl)-2,5-diphenyltetrazolium bromide as a colorant), the percentage of surviving cells was determined. As a control sample, cells not treated with cytotoxic drugs were used.

PC3 Cellular/Nucleus Accumulation Study. PC3 cells $\left(10^{5}\right.$ cells $\left./ \mathrm{ml}\right)$ were seated on Petri dishes with a glass bottom with a thickness of $0.17 \mathrm{~mm}$. The experiment was carried out the next day (for the complete spreading of the cells and the acquisition of characteristic morphology by them). There were 3 samples: cells incubation with DOX $(\mathrm{C} \sim 0.14 \mathrm{uM})$, cells incubation with $14(\mathrm{C} \sim 1.192 \mathrm{uM})$, and incubation with a solvent $\left(\mathrm{H}_{2} \mathrm{O}\right)$ for $2 \mathrm{~h}$. During incubation, cells were in phosphate-buffered saline (PBS) with the addition of $10 \mathrm{mM}$ HEPES (to reduce autofluorescence due to components of the complete nutrient medium). Living cells were kept in a chamber with a maintained level of $\mathrm{CO}_{2}$, temperature, and humidity. DIC and DOX/14 fluorescence images (in the red fluorescent channel $(561 \mathrm{~nm})$ were obtained using a motorized inverted fluorescent microscope Eclipse Ti-E (Nikon) equipped with an iXon cooled EM-CCD camera (Andor), PerfectFocus (Nikon) autofocus system, and Plan Apo 40x lens $(\mathrm{NA}=0.95)$. For DAPI vizualization, the cell preparations were fixed in $3.7 \%$ formaldehyde (Sigma-Aldrich, USA) prepared on PBS: washing from the retainer - 3 times for $5 \mathrm{~min}$. Next, $0.2 \mu \mathrm{g} / \mathrm{mL}$ DAPI (Cayman Chemical Company, USA) was added: washing - 3 times for 5 min (PBS); further shooting in 2 channels - $450 \mathrm{~nm}$ for DAPI and 561 for DOX and 14. Image processing was performed in the NIS-elements imaging software and in ImageJ.

\section{ASSOCIATED CONTENT}

\section{S Supporting Information}

The Supporting Information is available free of charge on the ACS Publications website at DOI: 10.1021/acs.bioconjchem.8b00885.

\section{AUTHOR INFORMATION}

\section{Corresponding Author}

*Phone: +7 495 9394020. Fax: +7 495 9328846. E-mail: krasnovskayao@gmail.com.

\section{ORCID}

Olga O. Krasnovskaya: 0000-0002-4948-2747

Olga A. Fedorova: 0000-0001-7843-4157

Gediminas Jonusauskas: 0000-0002-2647-1439

Alexander G. Majouga: 0000-0002-5184-5551

\section{Author Contributions}

The manuscript was written through contributions of all authors. All authors have given approval to the final version of the manuscript.

Notes

The authors declare no competing financial interest.

\section{ACKNOWLEDGMENTS}

The study was supported by the Ministry of Science and Higher Education of the Russian Federation in the framework of Increase Competitiveness Program of NUST “MISiS” (No. K22018-008) (Implemented by a governmental decree dated $16^{\text {th }}$ of March 2013, N 211), the Russian Foundation for Basic Research [No. 18-33-01038] and the Russian Science Foundation [No. 17-74-30012]. Synthesis of naphthalimide dye, steady-state spectroscopic studies of FRET dye, and calculations of resonance energy transfer process characteristics were supported by the Russian Foundation for Basic Research [No. 1833-20111]. The cellular accumulation study was supported by the Russian Science Foundation [No. 17-15-01290].

\section{ABBREVIATIONS}

Dox, Doxorubicin; FRET, Förster resonance energy transfer; FITC, Fluorescein isothiocyanate

\section{REFERENCES}

(1) Shu, Y., Xie, B., Liang, Z., and Chen, J. (2017) Quercetin reverses the doxorubicin resistance of prostate cancer cells by downregulating the expression of c-met. Oncol. Lett. 15, 2252-2258.

(2) Du, Y., Long, X., Ami, J., Richey, M. D., Philippe, Marion, F. E., and David, G. I. K. (2018) Synthesis and Evaluation of Doxorubicin-Loaded Gold Nanoparticles for Tumor-Targeted Drug Delivery. Bioconjugate Chem. 29 (2), 420-430.

(3) Luu, A. Z., Biswajit, C., Mohammed, Al-O, Hwee, T., David, A. H., and Subodh, V. (2018) Role of Endothelium in Doxorubicin-Induced Cardiomyopathy. JACC: Basic to translation science. 3 (6), 861-870.

(4) Ding, G.-B., Junqing, S., Peng, Y., Binchun, L., Ying, G., and Zhuoyu, L. (2018) A Novel Doxorubicin Prodrug with GRP78 Recognition and Nucleus-Targeting Ability for Safe and Effective Cancer Therapy. Mol. Pharmaceutics 15 (1), 238-246.

(5) González-Méndez, I., Solano, J. D., and Porcu, P. (2019) Optimized synthesis, characterization and in vitro systematic evaluation of adamantane-doxorubicin prodrugs sensitive to $\mathrm{pH}$ in breast cancer cells. J. Mol. Struct. 1177 (5), 143-151.

(6) Kato, Y., Ozawa, S., Miyamoto, C., Maehata, Y., Suzuki, A., Maeda, T., and Baba, Y. (2013) Acidic extracellular microenvironment and cancer. Cancer Cell Int. 13 (1), 89-97.

(7) Griffiths, J. R. (1991) Are cancer cells acidic? Br. J. Cancer 64 (3), $425-427$.

(8) Han, J., and Burgess, K. (2010) Fluorescent Indicators for Intracellular pH. Chem. Rev. 110 (5), 2709-2728.

(9) Helmlinger, G., Sckell, A., Dellian, M., Forbes, N. S., and Jain, R. K. (2002) Acid production in glycolysis-impaired tumors provides new insights into tumor metabolism. Clin. Cancer Res. 8 (4), 1284-1291.

(10) Poomthavorn, P., Wong, S. H., Higgins, S., Werther, G. A., and Russo, V. C. (2009) Activation of a prometastatic gene expression program in hypoxic neuroblastoma cells. Endocr.-Relat. Cancer 16, 9911004.

(11) Vukovic, V., and Tannock, H. (1997) Influence of low pH on cytotoxicity of paclitaxel, mitoxantrone and topotecan. Br. J. Cancer 75 (8), 1167-1172.

(12) Betof, A. S., Rabbani, Z. N., Hardee, M. E., Kim, S. J., Broadwa, G., Bentley, R. C., Snyder, S. A., Vujaskovic, Z., Oosterwijk, E., and Harris, L. N. (2012) Carbonic anhydrase IX is a predictive marker of doxorubicin resistance in early-stage breast cancer independent of HER2 and TOP2A amplification. Br. J. Cancer 106 (5), 916-922.

(13) Lotz, C., Kelleher, D. K., Gassner, B., Gekle, M., Vaupel, P., and Thews, O. (2007) Role of the tumor microenvironment in the activity and expression of the p-glycoprotein in human colon carcinoma cells. Oncol. Rep. 17 (1), 239-244.

(14) Thews, O., Dillenburg, W., Rosch, F., and Fellner, M. (2013) PET imaging of the impact of extracellular $\mathrm{pH}$ and MAP kinases on the p-glycoprotein (Pgp) activity. Adv. Exp. Med. Biol. 765, 279-286. 
(15) Xiong, S., Wang, Z., Liu, J., Deng, X., Lei, Y. C. X., and Tang, G. (2019) A pH-sensitive prodrug strategy to co-deliver DOX and TOS in TPGS nanomicelles for tumor therapy. Colloids Surf., B 173 (1), 346355.

(16) González-Méndez, I., Solano, J. D., Porcu, P., Ruiu, A., Yareli, R., and Rivera, E. (2019) Optimized synthesis, characterization and in vitro systematic evaluation of adamantane doxorubicin prodrugs sensitive to pH in breast cancer cells. J. Mol. Struct. 1177, 143-151.

(17) Ma, B., Zhuang, W., Wang, Y., Luo, R., and Wang, Y. (2018) pHsensitive doxorubicin-conjugated prodrug micelles with chargeconversion for cancer therapy. Acta Biomater. 70 (1), 186-196.

(18) Lee, E. S., Gao, Z., Kim, D., Park, K., Kwon, I. C., and Bae, Y. H. (2008) Super $\mathrm{pH}$-sensitive multifunctional polymeric micelle for tumor pHe specific TAT exposure and multidrug resistance. J. Controlled Release 129 (3), 228-236.

(19) Wang, Y., Li, L., Jiang, W., Yang, Z., and Zhang, Z. (2006) Synthesis and preliminary antitumor activity evaluation of a DHA and doxorubicin conjugate. Bioorg. Med. Chem. Lett. 16, 2974-2977.

(20) Swietach, P., Vaughan-Jones, R. D., Harris, A. L., and Hulikova, A. (2014) The chemistry, physiology and pathology of $\mathrm{pH}$ in cancer. Philos. Trans. R. Soc., B 369 (1638), 20130099.

(21) Majumdar, P., Bathula, C., Basu, S. M., Das, S. K., Agarwal, R., Hati, S., Singh, A., Sen, S., and Das, B. B. (2015) Design, synthesis and evaluation of thiohydantoin derivatives as potent topoisomerase I (Top1) inhibitors with anticancer activity. Eur. J. Med. Chem. 102, 540551.

(22) Chang, W. J., Kulkarni, M. V., and Sun, C. M. (2006) Traceless and Stere- oselective Synthesis of Tetrahydro- $\beta$-carbolinethiohydantoins by Microwave Irradiation. J. Comb. Chem. 8, 141-144.

(23) Roué, N., and Bergman, J. (1999) Synthesis of the marine alkaloid leucettamine B. Tetrahedron 55, 14729-14738.

(24) Fuentes, J., Salameh, B. A. B., Pradera, M. A., Fernández de Córdoba, F. J., and Gasch, C. (2006) Stereocontrolled synthesis of thiohydantoin spironucleosides from sugar spiroacetals. Tetrahedron 62, 97-111.

(25) Beloglazkina, E. K., Majouga, A. G., Romashkina, R. B., and Zyk, N. V. (2006) A novel catalyst for alkene epoxidation: a polymersupported CoIILCl2 $\{\mathrm{L}=2$-(alkylthio)-3-phenyl-5-(pyridine-2-ylmethylene)- 3,5-dihydro-4H-imidazole-4-one $\}$ complex. Tetrahedron Lett. 47, 2957-2959.

(26) Kuznetsova, O., Antipin, R. L., Udina, A. V., Krasnovskaya, O. O., Beloglazkina, E. K., Terenin, V. I., Koteliansky, V. E., Zyk, N. V., and Majouga, A. G. (2016) An Improved Protocol for Synthesis of 3Substituted 5-Arylidene-2-thiohydantoins: Two-step Procedure Alternative to Classical. Methods. J. Heterocyclic Chem. 53, 1570-1577.

(27) Tripathi, L. (2011) Design \& synthesis of $\mathrm{N}^{\prime}$-[substituted] pyridine-4- carbohydrazides as potential anticonvulsant agents. Eur. J. Med. Chem. 46 (2), 509-518.

(28) Finnerup, N. B. (2015) Pharmacotherapy for neuropathic pain in adults: a systematic review and meta-analysis. Lancet Neurol. 14, 162173.

(29) Shorvon, S. D. (2009) Drug treatment of epilepsy in the century of the ILAE: The second 50 years, 1959-2009. Epilepsia 50, 93-130.

(30) Green, J. R., Miller, L. H., Patsy, D., Burnett, A., and Ward, A. (1969) Clinical evaluation of albutoin. Neurology 19 (12), 1207-1215.

(31) Bridewell, D. J., Finlay, G. J., and Baguley, B. C. (1997) Differential actions of aclarubicin and doxorubicin: the role of topoisomerase I. Oncol Res. 9, 535-42.

(32) Capranico, G., Supino, R., Binaschi, M., Capolongo, L., Grandi, M. S., and Zunino, F. (1994) Influence of structural modifications at the $3^{\prime}$ and $4^{\prime}$ positions of doxorubicin on the drug ability to trap topoisomerase II and to overcome multidrug resistance. Mol. Pharmacol. 45 (5), 908-915.

(33) Gallois, L., Fiallo, M., and Garnier-Suillerot, A. (1998) Comparison of the interaction of doxorubicin, daunorubicin, idarubicin and idarubicinol with large unilamellar vesicles: Circular dichroism study. Biochim. Biophys. Acta, Biomembr. 1370 (1), 31-40.

(34) Nikiforov, T. T., and Beechem, J. M. (2006) Development of homogeneous binding assays based on fluorescence resonance energy transfer between quantum dots and Alexa Fluor fluorophores. Anal. Biochem. 357 (1), 68-76.

(35) Hanulia, T., Inami, W., Ono, A., and Kawata, Y. (2018) Fluorescence life-time measurement excited with ultraviolet surface plasmon resonance. Opt. Commun. 427, 266-270.

(36) Singharoy, D., Chowdhury, S., Mati, S. S., Ghosh, S., and Chatt, P. (2017) Electron Transfer Switching Mechanism of a Naphthalimide Derivative with its Solvatochromic Behaviour An Experimental and Theoretical Study with In Cell Investigations. Chem. - Eur. J. 23, 16516-16524.

(37) Wei, Y., Liao, R., Mahmood, A. A., Xu, H., and Zhou, Q. (2017) $\mathrm{pH}$-responsive $\mathrm{pHLIP}$ ( $\mathrm{pH}$ low insertion peptide) nanoclusters of super-paramagnetic iron oxide nanoparticles as a tumor-selective MRI con-trast agent. Acta Biomater. 55, 194-203.

(38) Chhikara, B. S., Jean, N., St., Mandal, D., Kumar, A., and Parang, K. (2011) Fatty acyl amide derivatives of doxorubicin: Synthesis and in vitro anticancer activities. Eur. J. Med. Chem. 46 (6), 2037-2042.

(39) Legigan, T., Clarhaut, J., Tranoy-Opalinski, I., Monvoisin, A., Renoux, B., Thomas, M., Le Pape, A., Lerondel, S., and Papot, S. (2012) The First Generation of $\beta$-Galactosidase-Responsive Prodrugs Designed for the Selective Treatment of Solid Tumors in Prodrug Monotherapy. Angew. Chem., Int. Ed. 51, 11606-11610.

(40) Hassan, F., El-Hiti, G. A., Abd-Allateef, M., and Yousif, E. (2017) Cytotoxicity anticancer activities of anastrozole against breast, liver hepatocellular, and prostate cancer cells. Saudi Medical Journal. 38 (4), 359-365.

(41) Hematyar, M., Soleimani, M., Es-haghi, A., and Rezaei Mokarram, A. (2018) Synergistic co-delivery of doxorubicin and melittin using functionalized magnetic nanoparticles for cancer treatment: loading and in vitro release study by LC-MS/MS. Artif. Cells, Nanomed., Biotechnol. 19, 1-10.

(42) Kleeberger, L., and Rottinger, E. M. (1993) Effect of pH and moderate hyperthermia on doxorubicin, epirubicin and aclacinomycin A cytotoxicity for Chinese hamster ovary cells. Cancer Chemother. Pharmacol. 33 (2), 144-148.

(43) Nitiss, J. L. (2009) Targeting DNA topoisomerase II in cancer chemotherapy. Nat. Rev. Cancer 9 (5), 338-350.

(44) Chaikomon, K., Chattong, S., Chaiya, T., Tiwawech, D., SritanaAnant, Y., Sereemaspun, A., and Manotham, K. (2018) Doxorubicinconjugated dexamethasone induced MCF-7 apoptosis without entering the nucleus and able to overcome MDR-1-induced resistance. Drug Des., Dev. Ther. 12, 2361-2369.

(45) Stewart, J. P. (2007) Optimization of parameters for semiempirical methods V: Modification of NDDO approximations and application to 70 elements. J. Mol. Model. 13, 1173-1213. 